\title{
Comparing the effects of inorganic nitrate and allopurinol in renovascular complications of metabolic syndrome in rats: role of nitric oxide and uric acid
}

\author{
Soha S. Essawy ${ }^{1}$, Khaled A. Abdel-Sater ${ }^{2}$, Amani A. Elbaz
}

1Department of Pharmacology, Faculty of Medicine, Suez Canal University, Ismailia, Egypt ${ }^{2}$ Department of Physiology, Faculty of Medicine, Al-Azhar University, Assiut, Egypt ${ }^{3}$ Department of Physiology, Faculty of Medicine, Suez Canal University, Ismailia, Egypt

Submitted: 25 January 2012

Accepted: 31 March 2012

Arch Med Sci 2014; 10, 3: 537-545

DOI: 10.5114/aoms.2013.33222

Copyright $\odot 2014$ Termedia \& Banach
Corresponding author: Khaled A. Abdel-Sater Eliwa Department of Physiology Faculty of Medicine Al-Azhar University King Abdul

Aziz University

Rabigh, KSA, Egypt

Phone: +966502470699

E-mail: khaled_71111@yahoo.com

\section{Abstract}

Introduction: The epidemic of metabolic syndrome is increasing worldwide and correlates with elevation in serum uric acid and marked increase in total fructose intake. Fructose raises uric acid and the latter inhibits nitric oxide bioavailability. We hypothesized that fructose-induced hyperuricemia may have a pathogenic role in metabolic syndrome and treatment of hyperuricemia or increased nitric oxide may improve it. Material and methods: Two experiments were performed. Male Sprague-Dawley rats were fed a control diet or a high-fructose diet to induce metabolic syndrome. The latter received either sodium nitrate or allopurinol for 10 weeks starting with the $1^{\text {st }}$ day of fructose to evaluate the preventive role of the drugs or after 4 weeks to evaluate their therapeutic role.

Results: A high-fructose diet was associated with significant $(p<0.05)$ hyperuricemia $(5.9 \pm 0.5 \mathrm{mg} / \mathrm{dl})$, hypertension $(125.2 \pm 7.8 \mathrm{~mm} \mathrm{Hg})$, dyslipidemia and significant decrease in tissue nitrite $(27.4 \pm 2.01 \mathrm{mmol} / \mathrm{l})$. Insulin resistance, as manifested by HOMAIR $(20.6 \pm 2.2)$ and QUICKI $(0.23 \pm 0.01)$ indices, as well as adiposity index $(12.9 \pm 1.1)$ was also significantly increased $(p<0.1)$. Sodium nitrate or allopurinol was able to reverse these features significantly $(p<0.05)$ in the preventive study better than the therapeutic study.

Conclusions: Fructose may have a major role in the epidemic of metabolic syndrome and obesity due to its ability to raise uric acid. Either sodium nitrate or allopurinol can prevent this pathological condition by different mechanisms of action.

Key words: fructose, hyperuricemia, insulin resistance, metabolic syndrome.

\section{Introduction}

Metabolic syndrome is a worldwide problem, which refers to a constellation of coronary heart disease (CHD) risk factors including obesity and abdominal fat distribution, disorders of glucose and lipid metabolism, and hypertension [1, 2]. In addition, various other abnormalities of uric acid, inflammation, homeostasis, and fibrinolysis are often considered part of this syndrome [3].

The prevalence of metabolic syndrome is increasing and it is considered one of the main threats to human health worldwide [4]. The epidemic correlates with pronounced changes in the environment, behavior and lifestyle [5].

Several studies have suggested that fructose-induced hyperuricemia may play a pathogenic role in metabolic syndrome. This is consistent with the increased consumption of fructose-containing beverages and the epidemic 
of diabetes and obesity [6]. In contrast to the metabolic effects of other sugars, fructose induces hyperuricemia through the stimulation of nucleotide catabolism via the conversion of hepatic adenosine triphosphate to adenosine diphosphate by fructokinase and it may retard urinary excretion of uric acid [7]

Uric acid induces gene expression of chemokines and growth factors, such as monocyte chemoattractant protein-1 and platelet-derived growth factor, and stimulates proliferation of vascular smooth muscle cells [8].

Another potential mechanism activated by uric acid is oxidative stress. In the extracellular environment, urate can scavenge hydroxyl radical, singlet oxygen and peroxynitrite, especially when combined with ascorbic acid or thiols [9]. On the other hand, uric acid loses its antioxidant ability in the hydrophobic environment [10]. It was shown that soluble uric acid - alone or combined with peroxynitrite - stimulates an increase in nicotinamide adenine dinucleotide phosphate (NADPH) oxidase activity and increases production of reactive oxygen species in mature adipocytes, which result in increased protein nitrosylation and lipid oxidation [11, 12].

Uric acid also inhibits nitric oxide bioavailability and, because insulin requires nitric oxide to stimulate glucose uptake, there is a possibility that fructose-induced hyperuricemia and insulin resistance are partially prevented by lowering serum uric acid [13].

Recent studies have demonstrated that in the bioactivation of nitrate, nitrite anion is an intermediate and this more reactive compound is further metabolized to nitric oxide, nitrosothiols and other bioactive nitrogen oxide tissues [14].

Administration of nitrate or nitrite to humans and rodents is clearly associated with nitric oxidelike bioactivity, as demonstrated by increases in cyclic guanosine monophosphate formation [15], vasodilatation [16], reduction in blood pressure [17] and inhibition of platelet function [18].

Therefore, this study was designed to investigate and compare the role of the preventive and therapeutic effects of inorganic nitrate and allopurinol on metabolic syndrome features and renovascular complications to improve the role of NO and uric acid in pathogenesis of metabolic syndrome.

\section{Material and methods}

\section{Chemicals and drugs}

Allopurinol was purchased from Sigma-Aldrich Chemical Company (St. Louis, MO, USA). Normal saline solution (sodium chloride $0.9 \%$ ) and fructose were purchased from AlGomhoria Pharmaceutical Co. (Cairo, Egypt). Sodium nitrate was obtained from MUP Pharmaceutical Co. (Ismailia, Egypt). All the commercial assay kits were purchased from Biodiagnostic ${ }^{\circledR}$ (Cairo, Egypt).

\section{Animals}

Sixty-four Sprague-Dawley adult male rats (180$200 \mathrm{~g}$ ) were purchased from the National Research Center, Cairo, Egypt. Animals were housed in wiremesh cages with a normal light-dark cycle at a constant temperature of $22-24^{\circ} \mathrm{C}$ throughout the experiment. They were placed on a standard chow ad libitum for 1 week to adapt to the laboratory environment before experiments. The study was designed to avoid suffering and limit the number of animals used and all experimental protocols were approved by the institutional animal care and use committee at the Faculty of Medicine, Suez Canal University (Ismailia, Egypt).

\section{Study design}

Two experiments were conducted in this study; rats were divided into four groups in each experiment.

\section{Experiment I: treatment of fructose-induced hyperuricemia with inorganic nitrate or allopurinol (therapeutic regimen)}

To assess the therapeutic effect of either inorganic nitrate or allopurinol in fructose-induced metabolic syndrome, two groups of rats were used. Rats $(n=24)$ were fed a high-fructose diet or a control diet $(n=8)$. The high-fructose diet contained $60 \%$ fructose, whereas the control diet contained $46 \%$ starch as the carbohydrate. The caloric content of these diets was $3.6 \mathrm{kcal} / \mathrm{g}$ and $3.1 \mathrm{kcal} / \mathrm{g}$, respectively [19]. At 4 weeks, blood pressure was measured, blood samples were obtained at 11 a.m. after overnight fasting, and then the fructose-fed group was subdivided into 3 sub-groups of 8 animals each. The untreated fructose group served as a positive control group. The sodium nitrate and allopurinol groups received either sodium nitrate $(150 \mathrm{mg} / \mathrm{kg}$ ) [20] or allopurinol $(10 \mathrm{mg} / \mathrm{kg})$ [20] dissolved in normal saline by oral gavage once daily for an additional 6 weeks.

\section{Experiment II: prevention of fructose-induced hyperuricemia with sodium nitrate or allopurinol (preventive regimen)}

To assess their effect in preventing metabolic syndrome, sodium nitrate and allopurinol in the same mentioned doses were initiated on the day when the high-fructose diet was given from week 0 to week 10. Four groups were used in this preventive study: control, fructose, fructose sodium nitrate and fructose_allopurinol ( $n=8$ each).

\section{Measurement of body weight}

Rats were pair-fed to ensure equivalent caloric intake, thereby avoiding the influence of different food intake on the metabolic abnormalities. Body weight was measured weekly [21]. 


\section{Measurement of mean blood pressure}

All animals were preconditioned for mean blood pressure measurements one week before the experiment by the tail-cuff method (Data acquisition system mp140, USA). Blood pressure was measured at baseline, at 4 weeks and at 10 weeks. The mean of three successive measurements was taken [22].

\section{Blood glucose determination and sample collection}

At the end of the $4^{\text {th }}$ week and at the end of the study, rats were fasted overnight and fasting blood glucose was determined with an automatic blood glucose meter (Super Glucocard, Japan) using blood samples from the tail vein. At the end of the study, rats were anesthetized with thiopental sodium (50 mg/kg) [23] and killed by decapitation. Blood samples were collected by cardiac puncture, centrifuged at $2000 \mathrm{rpm}$ for $15 \mathrm{~min}$ within $30 \mathrm{~min}$ of collection and stored at $-80^{\circ} \mathrm{C}$ until assayed.

\section{Enzyme-linked immunosorbent assay for insulin}

Serum insulin was determined at the $4^{\text {th }}$ week and the end of the study using a rat insulin ultrasensitive ELISA kit (Crystal Chem Inc., Downers Grove, IL 60515, USA) according to the manufacturer's instructions. Reactions were quantified by optical density using an automated ELISA reader.

\section{Calculation of insulin resistance}

Insulin resistance was determined using the homeostasis model assessment index for insulin resistance (HOMA-IR) using the following formula: HOMA-IR index $=[$ fasting glucose $(\mathrm{mmol} / \mathrm{l}) \times$ fasting insulin $(\mu \mathrm{U} / \mathrm{ml})] / 22.5$ [24]. To assess insulin sensitivity, the quantitative insulin sensitivity check index was used: (QUICKI) $=1 /($ log fasting insulin $(\mu \mathrm{U} / \mathrm{ml})+$ log fasting glucose $(\mathrm{mg} / \mathrm{dl}))$. QUICKI predicts insulin sensitivity, with lower values representing more insulin resistance [25].

\section{Processing of adipose tissue}

The retroperitoneal adipose tissue from each rat was totally removed and weighed at the end of the study to be used for calculation of the adiposity index: adipose tissue index $=$ (retroperitoneal adipose tissue weight / body weight) $\times 100$.

\section{Biochemical assays}

\section{Serum uric acid, creatinine and urea}

Serum uric acid was determined at 4 weeks and at the end of the study [26]. Serum creatinine [26] and urea [27] levels were measured at the end of the study.

\section{Urinary uric acid}

At the end of the study, rats in each group were individually housed in metabolic cages for $24 \mathrm{~h}$ urine collection, and continued to have free access to water and food. Urine samples were used for estimation of uric acid [26].

\section{Lipid profile}

Serum triglycerides (TGs) [28], total cholesterol [29] and high density lipoprotein cholesterol (HDL-C) [30] were measured at the end of the study. Low density lipoprotein (LDL) was calculated according to the following formula: serum LDL level = total cholesterol - ((triglycerides/5) + HDL) [31].

\section{Assay of total nitrite in renal tissue homogenate (Griess reaction)}

The total nitrite concentration level was measured in $100 \mathrm{mg}$ renal tissue homogenate - as an indicator for nitric oxide production - at the end of the study according to the method described by Green et al. [32]. All the colorimetric assays were performed using a UV-visible spectrophotometer (UV-1601-PC, Shimadzu, Japan).

\section{Statistical analysis}

The data were coded and entered using the statistical package SPSS version 17 (Chicago, IL, USA). The results were expressed as mean \pm S.E.M. Statistical analysis was performed using one-way analysis of variance (ANOVA) followed by post hoc multiple comparison Bonferroni test, to test the significance of differences among group means. $P$ value of $<0.05$ was considered statistically significant at confidence interval 95\%.

\section{Results}

\section{Effect of the high-fructose diet in induction of features of metabolic syndrome}

Oral administration of a high-fructose diet for 4 weeks in rats resulted in development of features of metabolic syndrome manifested by significant increase $(p<0.05)$ in mean blood pressure (BP), serum uric acid and fasting insulin levels with mean values of $125.2 \pm 7.8 \mathrm{~mm} \mathrm{Hg}, 5.9 \pm 0.5 \mathrm{mg} / \mathrm{dl}$ and $53 \pm 1.7 \mu \mathrm{U} / \mathrm{I}$ respectively as compared with rats fed a control diet with mean values of $62.7 \pm 4.7 \mathrm{~mm} \mathrm{Hg}$, $1.8 \pm 0.2 \mathrm{mg} / \mathrm{dl}$ and $42.2 \pm 1.8 \mu \mathrm{U} / \mathrm{l}$ respectively. On the other hand, the body weight of fructose-fed rats did not differ significantly compared with rats fed a normal diet: $225 \pm 10.2$ g vs. $231 \pm 10.1$ g respectively (data not shown).

\section{Mean blood pressure}

To examine the effect of sodium nitrate and allopurinol after development of metabolic syn- 
drome, one-third of the fructose-fed rats were treated with sodium nitrate and one-third were treated with allopurinol for 6 additional weeks. Sodium nitrate significantly $(p<0.05)$ reduced mean blood pressure while allopurinol induced a non-significant decrease in blood pressure compared to fructosefed rats (Figure $1 \mathrm{~A}$ ). The present study also examined the effectiveness of sodium nitrate and allopurinol in preventing the development of metabolic syndrome. The drugs were given simultaneously with the high-fructose diet from the starting point to avoid fructose-induced metabolic syndrome. As shown in Figure $1 \mathrm{~B}$, the elevation of mean blood pressure induced by the high-fructose diet was sig- nificantly $(p<0.05)$ decreased over the 10-week period by using any of the drugs.

\section{Fasting blood glucose, insulin and insulin resistance}

Although fructose-fed rats did not develop significant fasting hyperglycemia, they developed significant $(p<0.05)$ fasting hyperinsulinemia and a significant $(p<0.05)$ increase in insulin resistance compared to controls. Insulin resistance, as measured by HOMA-IR and QUICKI, was reversed significantly by either sodium nitrate or allopurinol compared to the fructose group in the therapeutic or

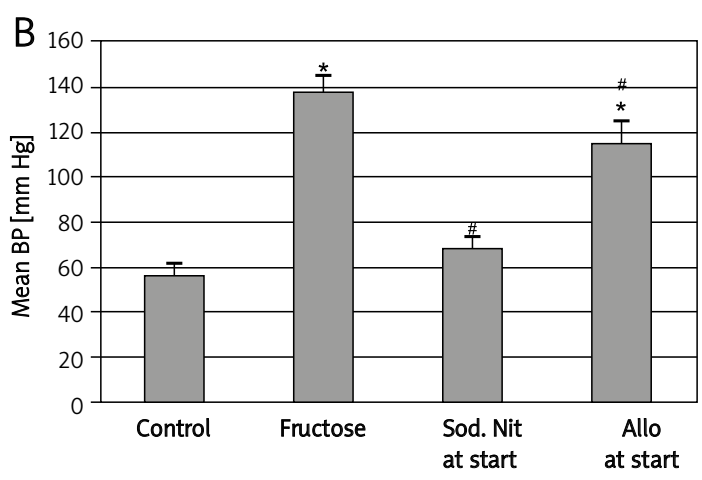

Figure 1. Mean blood pressure (BP) of experimental groups after 6 weeks (A) or 10 weeks (B) oral therapy of sodium nitrate (sod. Nit) $150 \mathrm{mg} / \mathrm{kg} /$ day or allopurinol (Allo) $10 \mathrm{mg} / \mathrm{kg} /$ day in rats with metabolic syndrome induced by $60 \%$ fructose in diet. Results are mean \pm SEM and analyzed by one-way ANOVA and Bonferroni post-hoc test *Significant compared to control group, \#significant compared to fructose group

Table I. Fasting blood glucose, insulin, HOMA-IR and QUICKI in fructose-induced metabolic syndrome in rats after therapeutic and preventive interventions with either sodium nitrate or allopurinol

\begin{tabular}{|c|c|c|c|c|c|c|c|c|c|c|}
\hline \multirow[t]{2}{*}{ Parameter } & \multicolumn{5}{|c|}{ Therapeutic regimen } & \multicolumn{5}{|c|}{ Preventive regimen } \\
\hline & Control & Fructose & $\begin{array}{l}\text { Sodium } \\
\text { nitrate }\end{array}$ & Allo & $\begin{array}{l}\text { Value } \\
\text { of } F\end{array}$ & Control & Fructose & $\begin{array}{l}\text { Sodium } \\
\text { nitrate }\end{array}$ & Allo & $\begin{array}{c}\text { Value } \\
\text { of } F\end{array}$ \\
\hline $\begin{array}{l}\text { Fasting } \\
\text { glucose } \\
{[\mathrm{mmol} / \mathrm{l}]}\end{array}$ & $5.9 \pm 0.4$ & $7.5 \pm 1.2$ & $6.2 \pm 0.9$ & $6.0 \pm 1.3$ & 5.54 & $5.9 \pm 0.4$ & $7.2 \pm 0.4$ & $6.2 \pm 0.3$ & $6.3 \pm 0.4$ & 6.54 \\
\hline $\begin{array}{l}\text { Fasting } \\
\text { insulin } \\
{[\mu \mathrm{U} / \mathrm{ml}]}\end{array}$ & $49.4 \pm 3.5$ & $61.8 \pm 1.4^{\star}$ & $59.3 \pm 3.1^{\star}$ & $61.2 \pm 3.1^{\star}$ & 14.56 & $49.4 \pm 3.5$ & $61.8 \pm 4.4^{*}$ & $55.8 \pm 2.1^{\star \#}$ & $52.9 \pm 2.7^{\#}$ & 18.35 \\
\hline HOMA-IR & $13 \pm 0.9$ & $20.6 \pm 2.2^{*}$ & $16.3 \pm 1.9^{*, \#}$ & $16.3 \pm 1.4^{\star, \#}$ & 16.32 & $13 \pm 0.9$ & $19.8 \pm 0.9^{\star}$ & $15.3 \pm 0.4^{\#}$ & $14.8 \pm 0.8^{\#}$ & 16.52 \\
\hline QUICKI & $0.27 \pm 0.02$ & $0.23 \pm 0.01^{\star}$ & $0.25 \pm 0.01^{*, \#}$ & $0.25 \pm 0.00^{*}$ & 17.11 & $0.27 \pm 0.02$ & $0.24 \pm 0.09^{*}$ & $0.26 \pm 0.01^{\#}$ & $0.26 \pm 0.02^{\#}$ & 16.39 \\
\hline $\begin{array}{l}\text { Body } \\
\text { weight [g] }\end{array}$ & $287.5 \pm 8$ & $255.0 \pm 12.4$ & $270.3 \pm 8$ & $284.5 \pm 7.4$ & 2.64 & $287.5 \pm 8$ & $280.0 \pm 3.8$ & $285.3 \pm 4.5$ & $270.0 \pm 3.9$ & 1.07 \\
\hline $\begin{array}{l}\text { Adipose } \\
\text { tissue [g] }\end{array}$ & $16.0 \pm 1.2$ & $32.9 \pm 1.5^{*}$ & $29.5 \pm 0.8^{*}$ & $21.1 \pm 1.9^{*, \#, @ ~}$ & 30.837 & $16.0 \pm 1.2$ & $32.7 \pm 1.5^{\star}$ & $24.1 \pm 0.8^{\star, \#}$ & $21.1 \pm 1.9^{*, \#}$ & 34.0 \\
\hline $\begin{array}{l}\text { Adiposity } \\
\text { index }\end{array}$ & $5.6 \pm 0.4$ & $12.9 \pm 1.1^{\star}$ & $10.9 \pm 0.3^{*}$ & $7.4 \pm 0.6^{\#, @(~}$ & 27.06 & $5.6 \pm 0.4$ & $11.7 \pm 0.9^{\star}$ & $8.4 \pm 0.6^{*, \#}$ & $7.8 \pm 0.1^{\star, \#}$ & 27.82 \\
\hline
\end{tabular}

HOMA-IR - homeostatic model assessment for insulin resistance. QUICKI - quantitative insulin sensitivity check index. Rats fed $60 \%$ fructose diet or a control diet for 10 weeks. Oral sodium nitrate $150 \mathrm{mg} / \mathrm{kg} / \mathrm{d}$ or allopurinol (Allo) $10 \mathrm{mg} / \mathrm{kg} /$ day was used for 6 weeks in the therapeutic regimen or for 10 weeks in the preventive regimen. Results are mean \pm SEM and analyzed by one-way ANOVA and Bonferroni post-hoc test. $N=8 .{ }^{*}$ Significant compared to control group at $p<0.05$, \#significant compared to fructose group at $p<0.05$, @significant compared to sodium nitrate group at $p<0.05$ 
preventive regimen. In addition, both drugs also induced a significant decrease in insulin level in the preventive regimen (Table I).

\section{Adiposity index}

Although body weight did not change significantly between fructose-fed rats and controls, the adipose tissue index was significantly $(p<0.05)$ increased in fructose-fed rats compared to controls. In the therapeutic regimen, allopurinol significantly $(p<0.05)$ prevented the increase in adiposity index compared
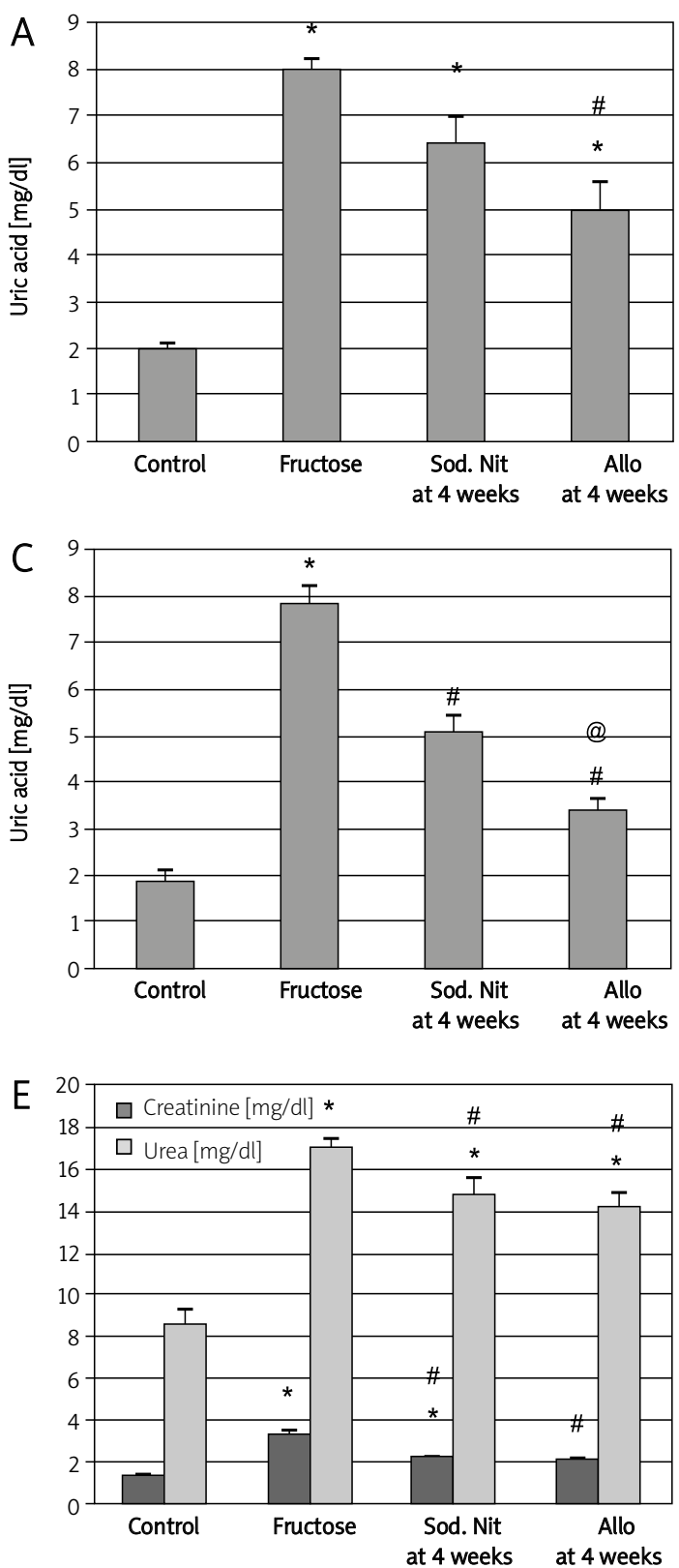

to fructose-fed rats and sodium nitrate-treated rats. On the other hand, both drugs resulted in a decrease in the adiposity index in the preventive regimen (Table I).

\section{Serum and urinary uric acid and serum creatinine and urea}

In accordance with the mechanism of action of allopurinol, in the therapeutic regimen, it showed a significant $(p<0.05)$ decrease in uric acid serum level, whereas the fructose-fed rats that did not
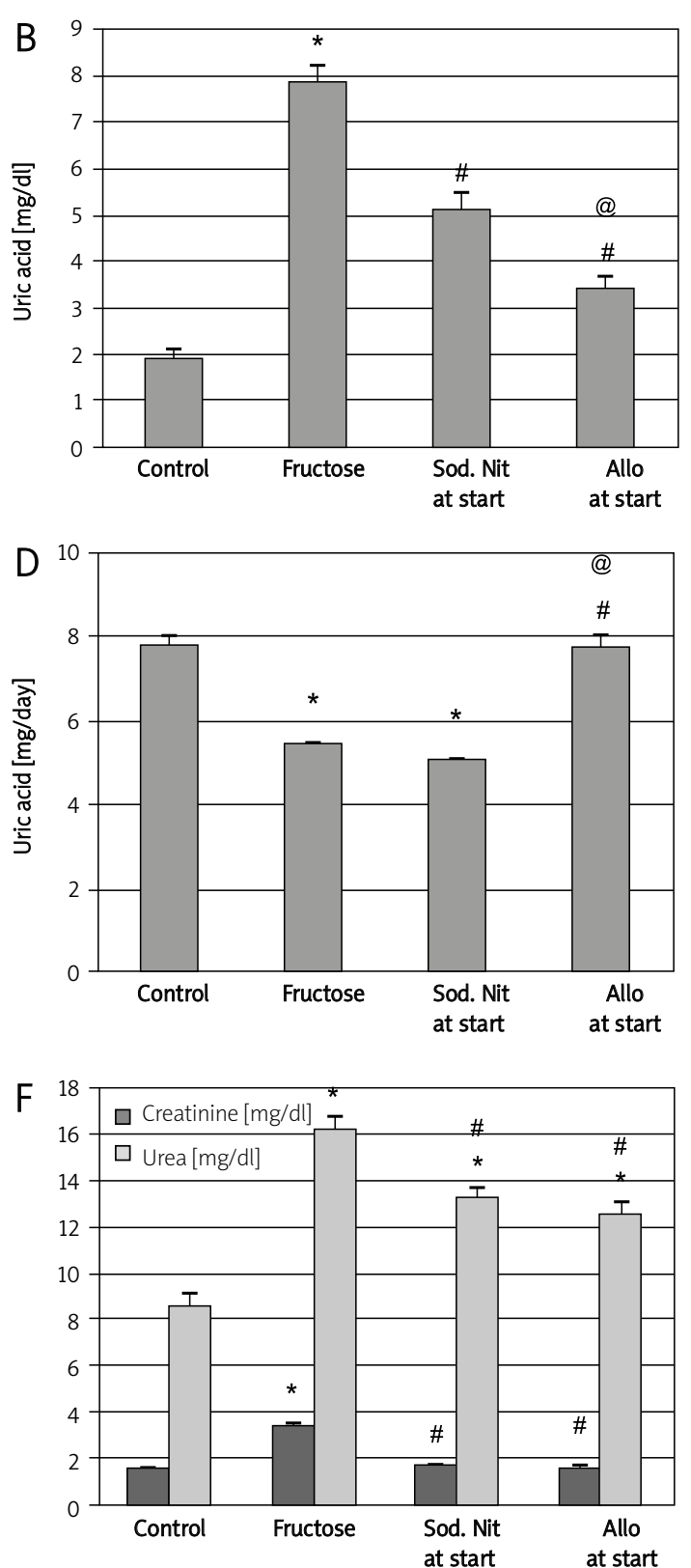

Figure 2. Serum uric acid $(\mathrm{mg} / \mathrm{dl})$, urinary uric acid $(\mathrm{mg} / \mathrm{day})$ and serum creatinine and urea $(\mathrm{mg} / \mathrm{dl})$ of experimental groups. Serum uric acid (A, B), urinary uric acid ( $\mathrm{mg} /$ day) $(\mathrm{C}, \mathrm{D})$ and serum creatinine and urea (E, F) after 6 weeks (A, C, E) or 10 weeks (B, D, F) oral therapy of sodium nitrate (sod. Nit) $150 \mathrm{mg} / \mathrm{kg} /$ day or allopurinol (Allo) $10 \mathrm{mg} / \mathrm{kg} /$ day in rats with metabolic syndrome induced by $60 \%$ fructose in diet

Results are mean \pm SEM and analyzed by one-way ANOVA and Bonferroni post-hoc test. *Significant compared to control group, "significant compared to fructose group, @significant compared to sodium nitrate group 
receive treatment or received sodium nitrate continued to be hyperuricemic (Figure $2 \mathrm{~A}$ ).

On the other hand, in the preventive regimen, both sodium nitrate and allopurinol resulted in a significant decrease in uric acid serum level compared to fructose-fed non-treated rats and the beneficial effect of allopurinol was significant compared to sodium nitrate ( $p<0.05$, Figure 2 B). In addition, we examined the urinary excretion of uric acid in these animals to clarify the mechanisms of hyperuricemia in fructose-fed rats. Fructose-fed rats had lower urinary excretion of uric acid. Interestingly, allopurinol - but not sodium nitrate - significantly prevented and reversed the reduced excretion of uric acid in fructose-fed rats $(p<0.05$, Figures 2 C, 2 D). The urinary excretion of uric acid was normalized in the preventive regimen.

Again, the high-fructose diet induced a significant $(p<0.05)$ increase in serum creatinine and urea compared to controls. Administration of either sodium nitrate or allopurinol in both regimens resulted in improvement of renal function as manifested by a significant decrease in these serum levels compared to fructose-fed rats ( $p<0.05$, Figures 2 E, 2 F).

\section{Lipid profile}

Regarding lipid profile, the results of the current study showed that fructose-fed rats developed a significant $(p<0.05)$ increase in serum TGs, cholesterol and LDL and a significant $(p<0.05)$ decrease in HDL serum levels compared to controls. Administration of sodium nitrate resulted in a significant decrease in TGs in both therapeutic and preventive regimens and both sodium nitrate and allopurinol significantly normalized HDL serum level in both regimens compared to fructose-fed rats $(p<0.05$, Figures 3 A, 3 B). On the other hand, the tested drugs resulted in a non-significant improvement in total cholesterol and LDL serum levels compared to fructose alone-fed rats $(p>0.05$, data not shown).

\section{Nitrite level in renal tissue homogenate}

A shown in Figure 4, nitric oxide level was measured in renal tissue homogenate. Induction of metabolic syndrome by $60 \%$ fructose in diet induced a significant $(p<0.05)$ decrease in this level. In the therapeutic regimen, administration of sodium nitrate significantly $(p<0.05)$ increased its level again compared to the fructose-fed group and compared to the allopurinol-treated group (Figure $4 \mathrm{~A}$ ), while in the preventive regimen, both drugs induced a significant increase in its level compared to the fructose-fed group ( $p<0.05$, Figure 4 B).

\section{Discussion}

We have succeeded in inducing metabolic syndrome in experimental rats by administering $60 \%$ fructose for 4 weeks in the diet. Features of the syndrome were in the form of hypertension, hyperuricemia and hyperinsulinemia in accordance with Roncal et al. [22].

In an attempt to compare the effect of sodium nitrate and allopurinol on attenuating these mentioned features, sodium nitrate showed a significantly higher effect in reducing the mean arterial blood pressure compared to allopurinol. This could be attributed to the effect of sodium nitrate in inducing nitric oxide-like bioactivity in humans including a robust reduction in blood pressure, inhibition of platelet aggregation and improvement of endothelial function [15, 20, 33]. On the other hand, and in accordance with our study, it was found that allopurinol had a partial effect in preventing the rise
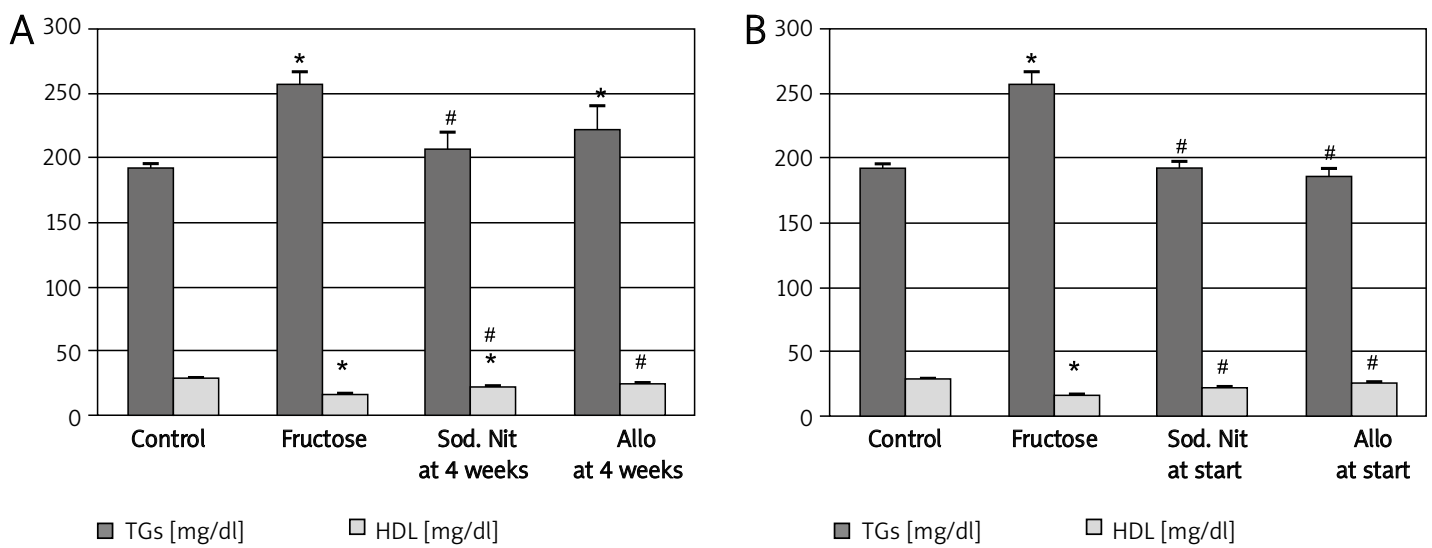

Figure 3. Serum triglycerides (TGs) and serum high-density lipoproteins (HDL) after 6 weeks (A) or 10 weeks (B) oral therapy of sodium nitrate (sod. Nit) $150 \mathrm{mg} / \mathrm{kg} /$ day or allopurinol (Allo) $10 \mathrm{mg} / \mathrm{kg} / \mathrm{day}$ in metabolic syndrome induced by $60 \%$ fructose in diet

Results are mean \pm SEM and analyzed by one-way ANOVA and Bonferroni post-hoc test. *Significant compared to control group, "\#significant compared to fructose group 

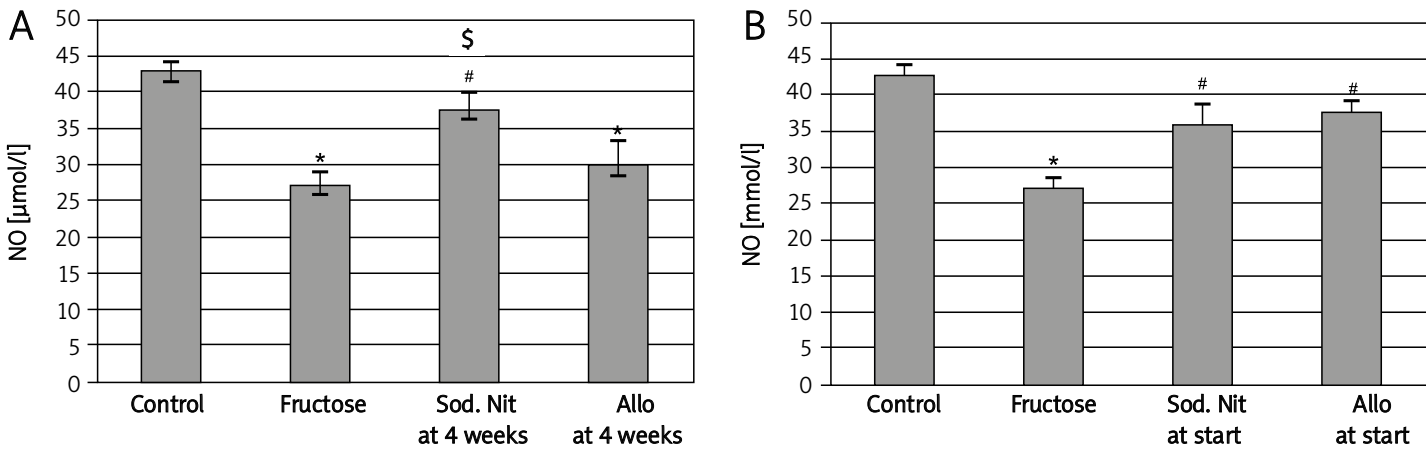

Figure 4. Nitrite level (NO) in $100 \mathrm{mg}$ renal tissue homogenate of experimental groups after 6 weeks (A) or 10 weeks (B) oral therapy of sodium nitrate (sod. Nit) $150 \mathrm{mg} / \mathrm{kg} /$ day or allopurinol (Allo) $10 \mathrm{mg} / \mathrm{kg} /$ day in rats with metabolic syndrome induced by $60 \%$ fructose in diet

Results are mean \pm SEM and analyzed by one-way ANOVA and Bonferroni post-hoc test. *Significant compared to control group, \#significant compared to fructose group, \$significant compared to allopurinol group

in arterial blood pressure when compared to captopril, a potent antihypertensive drug [22].

However, allopurinol was a potent drug in reducing both the hyperuricemia and the increase in the adipose tissue index induced by the metabolic syndrome compared to the effect of sodium nitrate. There is supporting evidence that uric acid may have a pathogenic role in metabolic syndrome. Hyperuricemia has been found to predict the development of both obesity and type II diabetes [34], as well as in secondary insulin resistance syndromes such as that associated with gout [35] or diuretic usage [36]. These data introduce the novel concept that uric acid may have a causal role in metabolic syndrome.

It is known that although fructose likely increases the production of uric acid, decreased urinary uric acid excretion could be due to an increase in uric acid reabsorption in proximal tubules [25]. The beneficial hypouricemic effect of allopurinol may be explained either by decreased uric acid synthesis [5] or according to Johnson et al. [37], who stated that hyperuricemic rats are known to develop renal vasoconstriction with a reduction of renal blood flow, and this is reversed by allopurinol. In turn, an increase in renal blood flow will result in increased uric acid excretion. According to that, by improving endothelial dysfunction and renal blood flow, the lowering of uric acid could paradoxically enhance excretion.

Regarding insulin resistance, our results were in accordance with previous studies which suggested that insulin resistance or hyperinsulinemia is associated with metabolic syndrome [38], enhanced urate reabsorption and reduced urate excretion in the kidney, leading to elevated serum uric acid concentrations [39]. Consistent with this observation is the finding that drugs which improve insulin sensitivity and lower insulin levels also reduce the level of serum uric acid in diabetic patients [40].
Uric acid potently reduces endothelial NO bioavailability in both cell culture and in experimental animal models [41]. In turn, reducing endothelial NO levels is a known mechanism for inducing insulin resistance [42]; thus endothelial NOS-deficient mice exhibit the features of metabolic syndrome [20]. This can be explained as insulin stimulates glucose uptake in skeletal muscle by increasing blood flow to these tissues through a nitric oxide-dependent pathway [42]. According to this, our study showed that allopurinol or sodium nitrate may have a beneficial role in metabolic syndrome by blocking hyperuricemia-induced endothelial dysfunction or providing nitric oxide to tissues respectively, a finding which was previously supported by many studies $[5,19]$.

Recent epidemiological evidence indicated that hyperuricemia might be a risk factor for renal dysfunction [43, 44]. In accordance with the previous studies, the current study showed that fructose resulted in hyperuricemia and attenuated renal function manifested by increase in serum creatinine and urea. On the other hand, allopurinol and sodium nitrate resulted in improvement of kidney function, probably due to hypouricemic properties and increased nitric oxide production respectively.

A recent study demonstrated that fructose upregulated the expression levels of renal specific transporters (rRST) and down-regulated the expression levels of organic anion transporters (rOAT) and organic cation transporters ( $\mathrm{rOCT} 1$ and $\mathrm{rOCT} 2$ ), with elevation of the regulator prostaglandin $\mathrm{E}_{2}\left(\mathrm{PGE}_{2}\right)$ and nitric oxide reduction, which might lead to excessive accumulation of endogenous and exogenous toxins, resulting in renal damage in fructose-fed rats. The dysregulation of these transporters, in addition to $P G E_{2}$ elevation and nitric oxide reduction, was reversed by allopurinol, rutin and quercetin [21].

Reviewing the effect on the lipid profile, we noticed that both drugs significantly increased HDL serum level but no significant effect was reported in the case of cholesterol or low-density lipoprotein 
serum levels. For the triglycerides, only sodium nitrate showed a significant decrease in its level in both therapeutic and prophylactic intervention. This is very consistent with the results of Carlström et al. [20], who reported that nitrate-treated endothelial nitric oxide synthase-deficient mice displayed lower levels of circulating triglycerides compared to untreated animals.

Although the role of uric acid in the metabolism of triglycerides remains unknown, uric acid might be involved in either the overproduction or the reduction of clearance of triglycerides. A decrease in the clearance of triglycerides in fructose-fed rats has been attributed to a reduction in lipoprotein lipase activity in endothelial cells [44]. An alternative explanation is the possibility that the de novo increase in purine synthesis observed in fructose-fed rats may be pathogenetically linked to hepatic fatty acid synthesis, resulting in overproduction of triglycerides [46].

In previous studies, it was reported that lowering uric acid improves dyslipidemia, which is consistent with our work [5, 47].

Regarding the potent effect of nitrates in increasing the tissue nitric oxide compared to allopurinol, we can explain that by the recently discovered ability of inorganic nitrates to be reduced to nitrite and then nitric oxide and other bioactive nitrogen oxides. In that way the deficiency in nitric oxide accompanying the metabolic syndrome could be replenished. It was assumed by certain studies that this deficiency is the result of polymorphism in the endothelial nitric oxide synthase gene in humans $[20,48,49]$.

Allopurinol also blocks oxidants generated by the xanthine oxidase pathway. Oxidants are involved in the pathogenesis of diabetes and its complications. It is therefore possible that the beneficial effects of allopurinol in metabolic syndrome may be attributed, in part, to the lowering of oxidants in addition to its effect on uric acid [10].

To test their prophylactic effects, we introduced both drugs from the beginning of the experiment with the same high-fructose diet in two other groups. All the features of metabolic syndrome were prevented: elevation of uric acid and mean arterial blood pressure, insulin resistance, hypertriglyceridemia and decreased $\mathrm{HDL}$, disturbance in adipose tissue index, elevated serum creatinine and urea, decrease in renal nitric oxide. These results turn our attention to the importance of enriching the daily diet with extensive intake of vegetables, the dominant dietary source of nitrate compounds $[20,50]$.

In conclusion, from the foregoing we can conclude that in metabolic syndrome we cannot count on allopurinol alone in dealing with the elevated blood pressure, but sodium nitrate should be considered first. At the same time, when considering hyperuricemia and dyslipidemia as fundamental disturbances in that syndrome, we proved that allopurinol is the treatment of choice. Our study proved the efficacy of each tested drug to partially attenuate the components of the metabolic syndrome, but in different ways.

Our fundamental recommendation is to test the efficacy of combining both of them. We hypothesize that adding their effects together could have great promise in reversing most of the features of metabolic syndrome.

\section{References}

1. Bao Y, Shang X, Zhou L, Hu R, Li Y, Ding W. Relationship between $\mathrm{N}$-terminal pro-B-type natriuretic peptide levels and metabolic syndrome. Arch Med Sci 2011; 7: 247-56.

2. Gluba A, Mikhailidis DP, Lip GY, Hannam S, Rysz J, Banach M. Metabolic syndrome and renal disease. Int J Cardiol 2012 [Epub ahead of print].

3. De Moura RF, Ribeiro C, De Oliveira JA, De Mello MA. Metabolic syndrome signs in Wister rats submitted to different high-fructose ingestion protocols. Br J Nutr 2009; 101: 1178-84.

4. Ford ES, Li C, Cook S, Choi HK. Serum concentrations of uric acid and the metabolic syndrome among US children and adolescents. Circulation 2007; 115: 2526-32.

5. Nakagawa T, Hu H, Zharikov S, et al. A causal role for uric acid in fructose-induced metabolic syndrome. Am J Physiol Renal Physiol 2006; 290: 625-31.

6. Stanhope KL, Havel PJ. Endocrine and metabolic effects of consuming beverages sweetened with fructose, glucose, sucrose, or high-fructose corn syrup. Am J Clin Nutr 2008; 88: 1733-7.

7. Gao X, Qi L, Qiao N, et al. Intake of added sugar and sugar-sweetened drink and serum uric acid concentration in US men and women. Hypertension 2007; 50: 306-12.

8. Corry DB, Eslami P, Yamamoto K, Nyby MD, Makino H, Tuck ML. Uric acid stimulates vascular smooth muscle cell proliferation and oxidative stress via the vascular reninangiotensin system. J Hypertens 2008; 26: 269-75.

9. Lin SD, Tsai DH, Hsu SR. Association between serum uric acid level and components of the metabolic syndrome. J Chin Med Assoc 2006; 69: 512-6.

10. Sui X, Church TS, Meriwether RA, Lobelo F, Blair SN. Uric acid and the development of metabolic syndrome in women and men. Metabolism 2008; 57: 845-52.

11. Chao HH, Liu JC, Lin J, Chen CH, Wu CH, Cheng TH. Uric acid stimulates endothelin-1 gene expression associated with NADPH oxidase in human aortic smooth muscle cells. Acta Pharmacol Scin 2008; 29: 1301-12.

12. Sautin Y, Nakagawa T, Zharikov S, Johnson RJ. Adverse effects of the classic antioxidant uric acidin adipocytes: NADPH oxidase-mediated oxidative/nitrosative stress. Am J Physiol Cell Physiol 2007; 293: 584-96.

13. Feig DI, Soletsky B, Johnson RJ. Effect of allopurinol on blood pressure of adolescents with newly diagnosed essential hypertension: a randomized trial. JAMA 2008; 300: 924-32.

14. Lundberg JO, Weitzberg E, Gladwin MT. The nitrate-nitritenitric oxide pathway in physiology and therapeutics. Nat Rev Drug Discov 2008; 7: 156-1.

15. Webb AJ, Patel N, Loukogeorgakis S, et al. Acute blood pressure lowering, vasoprotective, and antiplatelet properties of dietary nitrate via bioconversion to nitrite. Hypertension 2008; 51: 784-90. 
16. Jansson EA, Huang L, Malkey R, et al. A mammalian func tional nitrate reductase that regulates nitrite and nitric oxide homeostasis. Nat Chem Biol 2008; 4: 411-7.

17. Kapil V, Milsom AB, Okorie M, et al. Inorganic nitrate supplementation lowers blood pressure in humans: role for nitrite-derived NO. Hypertension 2010; 56: 274-81.

18. Zharikov SI, Krotova K, Hu H, et al. Uric acid decreases NO production and increases arginase activity in cultured pulmonary artery endothelial cells. Am J Physiol Cell Physiol 2008; 295: 1183-90.

19. Sánchez-Lozada LG, Le M, Segal M, Johnson RJ. How safe is fructose for persons with or without diabetes? Am J Clin Nutr 2008; 88: 1189-90.

20. Carlström M, Larsen FJ, Nyström T, et al. Dietary inorganic nitrate reverses features of metabolic syndrome in endothelial nitricoxide synthase-deficient mice. Proc Natl Acad Sci U SA 2010; 107: 17716-20.

21. Hu Q, Wang C, Li J, Zhang D, Kong L. Allopurinol, rutin, and quercetin attenuate hyperuricemia and renal dysfunction in rats induced by fructose intake: renal organic ion transporter involvement. Am J Physiol Renal Physiol 2009; 297: 1080-91.

22. Roncal CA, Reungjui S, Sánchez-Lozada LG, et al. Combi nation of captopril and allopurinol retards fructose-induced metabolic syndrome. Am J Nephrol 2009; 30: 399-404.

23. Vogler GA. Anesthesia and analgesia. In: The laboratory rat. Suckow MA, Weisbroth S, Franklin CL (eds). Elsevier Academic Press, New York 2006; 627-95.

24. Rudenski AS, Matthews DR, Levy JC, Turner R. Understanding insulin resistance: both glucose resistance and insulin resistance are required to model human diabetes. Metabolism 1991; 40: 908-17.

25. Reungjui S, Roncal CA, Mu W, et al. Thiazide diuretics exacerbate fructose-induced metabolic syndrome. J Am Soc Nephrol 2007; 18: 2724-31.

26. Spincer K. Analytical reviews in clinical biochemistry. Ann Clin Biochem 1986; 23: 1-25.

27. Fawcett JK, Scott JE. A rapid and precise method for the determination of urea. J Clin Pathol 1960; 13: 156-9.

28. Buccolo G, David H. Quantitative determination of serum triglycerides by use of enzymes. Clin Chem 1973; 19: 476-82.

29. Fasce CF, Vanderlinde RE. Factors affecting the results of serum cholesterol determinations: an interlaboratory evaluation. Clin Chem 1972; 118: 901-8.

30. Warnick GR, Nauck M, Rifai N. Evolution of methods for measurement of HDL-cholesterol: from ultracentrifugation to homogeneous assays. Clin Chem 2001; 47: 1579-96.

31. Friedewald WT, Levy RI, Fredrickson DS. Estimation of the concentration of low-density lipoprotein cholesterol in plasma, without use of the preparative ultracentrifuge. Clin Chem 1972; 18: 499-502.

32. Green LC, Wagner DA, Gloowski J, Skipper DL, Wishnok JS, Tannenbaum S. Analysis of nitrite, nitrate and [15N] nitrite in biological fluids. Anal Biochem 1982; 126: 131-8.

33. Larsen FJ, Ekblom B, Sahlin K, Lundberg JO, Weitzberg E. Effects of dietary nitrate on blood pressure in healthy volunteers. N Engl J Med 2006; 355: 2792-3.

34. Nakanishi N, Okamoto M, Yoshida H, Matsuo Y, Suzuki K, Tatara K. Serum uric acid and risk for development of hypertension and impaired fasting glucose or type II diabetes in Japanese male office workers. Eur J Epidemiol 2003; 18: 523-30.

35. Miao Z, Yan S, Wang J, et al. Insulin resistance acts as an independent risk factor exacerbating high-purine diet induced renal injury and knee joint gouty lesions. Inflam Res 2009; 58: 659-68.
36. Lindholm LH, Persson M, Alaupovic P, Carlberg B, Svensson A, Samuelsson O. Metabolic outcome during 1 year in newly detected hypertensives: results of the Antihypertensive Treatment and Lipid Profile in a North of Sweden Efficacy Evaluation (ALPINE study). J Hypertens 2003; 21: 1563-74.

37. Johnson RJ, Kang DH, Feig D, et al. Is there a pathogenetic role for uric acid in hypertension and cardiovascular and renal disease? Hypertension 2003; 41: 1183-90.

38. Athyros VG, Giouleme O, Ganotakis ES, et al. Safety and impact on cardiovascular events of long-term multifactorial treatment in patients with metabolic syndrome and abnormal liver function tests: a post hoc analysis of the randomised ATTEMPT study. Arch Med Sci 2011; 7: 796-805.

39. Shapiro A, Mu W, Roncal C, Cheng KY, Johnson RJ, Scarpace PJ. Fructose-induced leptin resistance exacerbates weight gain in response to subsequent high-fat feeding. Am J Physiol Regul Integr Comp Physiol 2008; 295: 1370-5.

40. Iwatani M, Wasada T, Katsumori K, Watanabe-Takahashi C, Kamatani N, Iwamoto Y. Troglitazone decreases serum uric acid concentrations in type II diabetic patients and non-diabetics. Diabetologia 2000; 43: 814-5.

41. Khosla UM, Zharikov S, Finch JL, et al. Hyperuricemia induces endothelial dysfunction. Kidney Int 2005; 67: 1739-42.

42. Lundberg JO, Gladwin MT, Ahluwalia A, et al. Nitrate and nitrite in biology, nutrition and therapeutics. Nat Chem Biol 2009; 5: 865-869.

43. Ritz E. Metabolic syndrome and kidney disease. Blood Purif 2008; 26: 59-62.

44. Ruilope LM, Garcia-Puig J. Hyperuricemia and renal function. Curr Hypertens Rep 2007; 3: 197-202.

45. Parks EJ, Hellerstein MK. Carbohydrate-induced hypertriacylglycerolemia: historical perspective and review of biological mechanisms. Am J Clin Nutr 2000; 71: 412-33.

46. Roncal-Jimenez CA, Lanaspa MA, Rivard CJ, et al. Sucrose induces fatty liver and pancreatic inflammation in male breeder rats independent of excess energy intake. Metabolism 2011; 60: 1259-70.

47. Cirillo P, Gersch MS, Mu W, et al. Ketohexokinasedependent metabolism of fructose induces proinflammatory mediators in proximal tubular cells. J Am Soc Nephrol 2009; 20: 457-9.

48. Monti LD, Barlassina C, Citterio L, et al. Endothelial nitric oxide synthase polymorphisms are associated with type 2 diabetes and the insulin resistance syndrome. Diabetes 2003; 52: 1270-5.

49. Fernandez ML, Ruiz R, Gonzalez MA, et al. Association of NOS3 gene with metabolic syndrome in hypertensive patients. Thromb Haemost 2004; 92: 413-8.

50. Hord NG, Tang Y, Ryan NS. Food sources of nitrates and nitrites: the physiologic context for potential health benefits. Am J Clin Nutr 2009; 90: 1-10. 